\title{
Commentary: Without short-term recovery, there is no long-term outcome after surgery for endocarditis
}

\author{
Ari A. Mennander, MD, PhD
}

From Tampere University Heart Hospital and Tampere University, Tampere, Finland.

Disclosures: Author has nothing to disclose with regard to commercial support.

Received for publication Oct 5, 2019; revisions received Oct 5, 2019; accepted for publication Oct 7, 2019; available ahead of print Oct 25,2019

Address for reprints: Ari A. Mennander, MD, PhD, Tampere University Heart Hospital, SDSKIR, PL 2000, Tampere, Finland (E-mail: ari.mennander@sydansairaala.fi).

J Thorac Cardiovasc Surg 2021;161:622-3

$0022-5223 / \$ 36.00$

Copyright (C) 2019 by The American Association for Thoracic Surgery

https://doi.org/10.1016/j.jtcvs.2019.10.065

Is repeated surgery for endocarditis safe? Currently, surgery is often the only option to effectively treat any endocarditis, whether it includes infectious prosthetic valve endocarditis (PVE) or native valve endocarditis (NVE). It is unknown whether endocarditis and repeated surgery or PVE alone impact outcome of the patients. The extension of infection and complexity of surgery are pondered against the comorbidities of the patient to maximize successful patient outcome. ${ }^{1}$

Weber and colleagues ${ }^{2}$ present an astute retrospective cohort study from 5 German surgical centers including 4300 patients with endocarditis undergoing surgery for either PVE or NVE. Early 30-day mortality in patients with PVE was almost twice as high as compared with patients with NVE. Mortality at 1 year after surgery almost doubled in both groups as compared with immediate postoperative outcomes. After Cox proportional hazards regression with multivariable adjustment, the authors found there was no longer a survival difference in between the groups, and repeated surgery was not in itself a trigger for followup complications or increased mortality. Concomitant surgery was performed significantly more often in patients with PVE as compared with patients with NVE. It was concluded that the greater early postoperative risk of patients undergoing surgery for PVE as compared with NVE patients was attributed to underlying comorbidities. It was also noted that many patients with PVE had negative blood bacteria cultures with lack of evident vegetations, and repeated imaging was strongly recommended.

Strictly taken, complete eradication of endocarditis after surgery cannot be editorialized, as the data represent a heterogenic group of patients undergoing various surgical interventions. Some patient variables were found missing and had to be removed from the analysis. The timing of PVE, the type of either mechanical or biological cardiac valve prosthesis, the use of homografts, history of intravenous drug use, subgroups of Staphylococcus bacteria, presence of abscess, and details of surgical techniques such as

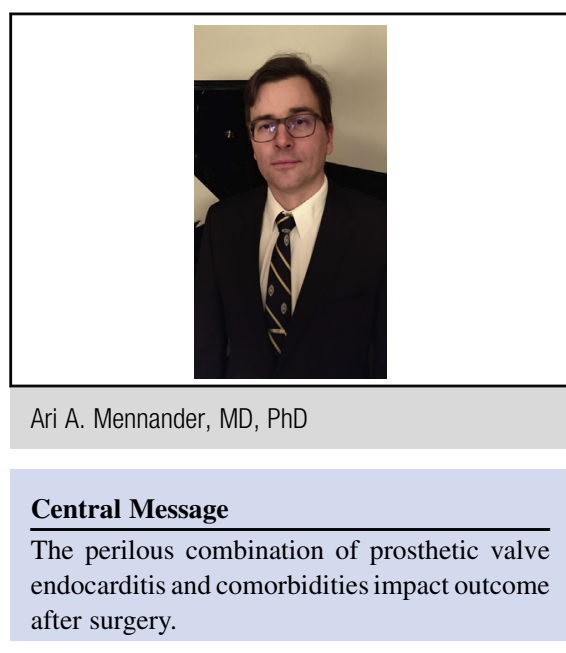

See Article page 609.

valve repair were not reported. Almost $14 \%$ of the missing data was assumed random in both groups. The mean followup time was limited.

Is this study at least partly reflecting the similar destiny after either first-time or repeated surgery despite endocarditis? All patients undergoing surgery for PVE underwent repeated surgery, whereas there were some patients with NVE who also had a history of previous cardiac surgery, albeit without endocarditis of a cardiac valve prosthesis. Some earlier studies have shown that despite technical complexity, repeated surgery in itself is not always associated with poor outcome.,

Weber and colleagues ${ }^{2}$ show that the increased risk of early mortality in patients with PVE undergoing surgery seems not to reflect later outcome; in other words, evaluation of early outcome may not suffice to weigh the ultimate recovery after endocarditis in patients with comorbidities. Endocarditis necessitates long-term follow-up and patient care. The diagnosis of PVE alone should not prevent surgeons from pursuing even repeated surgery, but short-term recovery is indispensable and must be ensured. The clinical presentation and outcome of patients with infective endocarditis following transcatheter and sutureless cardiac valve replacement would also be of high interest for clinicians.

\section{References}

1. Elgalad A, Arafat A, Elshazly T, Elkahwagy M, Fawzy H, Wahby E, et al. Surgery for active infective endocarditis of the aortic valve with infection extending beyond the leaflets. Heart Lung Circ. 2019;28:1112-20. 
2. Weber C, Petrov G, Luehr M, Aubin H, Tugtekin S-M, Borger MA, et al. Surgical results for prosthetic versus native valve endocarditis: a multicenter analysis. J Thorac Cardiovasc Surg. 2021;161:609-19.e10.

3. Stulak JM, Tchantchaleishvili V, Daly RC, Eleid MF, Greason KL, Dereani JA, et al. Conventional redo biological valve replacement over 20 years: surgical benchmarks should guide patient selection for transcatheter valve-in-valve therapy. J Thorac Cardiovasc Surg. 2018;156:1380-90.

4. Davierwala PM, Borger MA, David TE, Rao V, Maganti M, Yao TM, et al Reoperation is not an independent predictor of mortality during aortic valve surgery. J Thorac Cardiovasc Surg. 2006;131:329-35. 